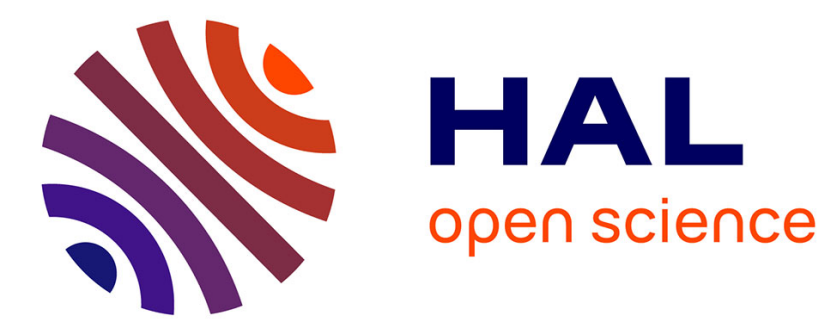

\title{
Maximizing returns for public funding of medical research with open-source hardware
}

\author{
J.M. Pearce
}

\section{To cite this version:}

J.M. Pearce. Maximizing returns for public funding of medical research with open-source hardware. Health Policy and Technology, 2017, 6 (4), pp.381-382. 10.1016/j.hlpt.2017.09.001 . hal-02111391

\section{HAL Id: hal-02111391 \\ https://hal.science/hal-02111391}

Submitted on 26 Apr 2019

HAL is a multi-disciplinary open access archive for the deposit and dissemination of scientific research documents, whether they are published or not. The documents may come from teaching and research institutions in France or abroad, or from public or private research centers.
L'archive ouverte pluridisciplinaire HAL, est destinée au dépôt et à la diffusion de documents scientifiques de niveau recherche, publiés ou non, émanant des établissements d'enseignement et de recherche français ou étrangers, des laboratoires publics ou privés. 
Preprint: J .M.Pearce. Maximizing Returns for Public Funding of Medical Research with Open-source Hardware. Health Policy and Technology. 6(4), 2017, pp. 381-382. https://doi.org/10.1016/j.hlpt.2017.09.001

\title{
Maximizing Returns for Public Funding of Medical Research with Open-source Hardware
}

\author{
J. M. Pearce
}

\section{Introduction - A Solution to High Medical Equipment Costs}

The success of both the historical clinical and scientific revolution was met with a massive expansion in research funding. ${ }^{1}$ Now, however, there are serious concerns in the research community that medical research funding expansion is not sustainable and may even decline. ${ }^{2,3}$ One aspect of medical research that is a large opportunity for cost reductions is medical research equipment. This is because the majority of medical care facilities and research labs have limited access to the best tools because of the exorbitant prices of proprietary equipment. ${ }^{4,5}$ In addition, proprietary medical equipment (even for simple screws) used in the clinical environment is far more expensive than experts would expect. ${ }^{6}$ Such "intellectual property rents" ${ }^{7,8}$ results in both reduced acute public health and slows the rate of medical science hampering future public health. The tremendous success of free and open source software (FOSS $)^{9}$ in driving innovation and low costs on the Internet, have led to the development of free and open-source hardware (FOSH). ${ }^{10}$ FOSS is computer software that is available in source code (open source) form and that can be used, studied, copied, modified, and redistributed without restriction, or with restrictions that only ensure that further recipients have the same rights under which it was obtained (free or libre). Under similar rights, FOSH provides the "code" for hardware including the bill of materials, schematics, instructions, computer aided designs (CAD), and other information needed to recreate a physical artifact. Similar to what is seen in FOSS development, FOSH leads to improved product innovation in a wide range of fields. ${ }^{11}$ The use of this open-source paradigm has become valuable for medical research as in obtaining costly clinical data. ${ }^{12}$ For example, the standards and communities that support the exchange of clinical trial data include Open mHealth ${ }^{13}$ and the Study Data Tabulation Model. ${ }^{14}$ Using data standards and trusted repositories such as the Open Science Framework provides the potential to create, store, and aggregate data sets without losing the rigor of the protocols established within individual clinical trials. ${ }^{15}$ However, FOSH goes beyond simply data access. By combining 3-D printing with open-source microcontrollers and electronics, hundreds of medical and scientific tools have already been developed. ${ }^{16,17}$ Scientists and medical equipment engineers can design, share and build on one another's work to develop technically superior and less costly medical devices.

For example, an evolving hand-held portable open-source combination colorimeter and nephelometer can be built to do COD and turbidity measurements for 7 to 15 times less than similar hand-held proprietary tools. ${ }^{18}$ In addition, more complex tools such as open mesoscopy ${ }^{19}$ have been developed. These tools save funding at each implementation. For example, an open source syringe pump, which can save between $\$ 150$ and $\$ 1,400$ per application, has resulted in millions of dollars of savings for users after the first few months of its release. ${ }^{20}$ By using FOSH designs that can be manufactured digitally the relatively minor development costs result in an enormous return on investment (ROI) for the scientific and medical communities. The lateral scaling of shared designs has created substantial value resulting in ROIs of hundreds and even thousands of percent. ${ }^{20}$

Similar opportunities are present for most medical and research equipment and such scaled replication provides savings between $90-99 \%$ of the conventional costs. ${ }^{16}$ To fully take advantage of 
this opportunity, funding is spent only once for development of libre medical and scientific equipment and then an immediate ROI is realized by the digital replication of the devices for the costs of materials and assembly. Currently, most FOSH medical tools fall within the low and medium range of costs, but with appropriate policy support all equipment including the most complex and high-end could be made with open hardware methods.

\section{Policies to Support Medical FOSH Development for Public Health}

Three policies, which would support medical FOSH development for public health include:

1. Identify, fund and disseminate medical FOSH designs of the most costly medical research and clinical equipment.

2. Fund validation studies of this medical FOSH so that medical researchers can trust and use the devices. For medical equipment the most important and costly component of hardware development is vetting and testing. Medical staff must be assured that the medical FOSH will function to specification. A repository should be maintained (e.g. the U.S. NIH's http://3dprint.nih.gov/) of the vetted designs along with methods of calibration and testing. This will largely eliminate the technical risks and liabilities for hospitals and labs to adopt the technology.

3. Enact purchasing policy preferences for validated medical FOSH resulting in increased competition for companies providing medical FOSH, which should further reduce costs. Overall these policies can be implemented at no net cost as existing funding for equipment development or purchase can be invested in medical FOSH design and testing. Even the most aggressive implementations provide a minimum of $100 \%$ ROI.

\section{Conclusions}

Latterly scaled replication of free and open source medical hardware provides savings between 90-99\% of the traditional costs, making medical and scientific equipment much more accessible for both clinical use and research. Medical research policy can maximize the return on investment by: 1) identifying, funding the development of and disseminating medical $\mathrm{FOSH}, 2$ ) funding validation studies of this equipment, and 3) enacting purchasing policy preferences for medical FOSH. These policies will directly save millions of dollars, while generating an ROI greater than $100 \%$ for public funding for health care, and supporting a rapid innovation in medical equipment design.

\section{References}

1. Kealey T, Nelson RR. The economic laws of scientific research. London: Macmillan; 1996.

2. Charlton BG, Andras P. Medical research funding may have over-expanded and be due for collapse. QJM. 2005;98(1):53-5.

3. Jaffe S. NIH budget shrinks despite Ebola emergency funds. The Lancet. 2015;385(9966):4045.

4. Balch C, Arias-Pulido H, Banerjee S, Lancaster AK, Clark KB, Perilstein M, Hawkins B, Rhodes J, Sliz P, Wilkins J, Chittenden TW. Science and technology consortia in US biomedical research: A paradigm shift in response to unsustainable academic growth. BioEssays. 2015;37(2):119-22. 
Preprint: J .M.Pearce. Maximizing Returns for Public Funding of Medical Research with Open-source Hardware. Health Policy and Technology. 6(4), 2017, pp. 381-382. https://doi.org/10.1016/j.hlpt.2017.09.001

5. Pearce JM. Maximizar la rentabilidad de la inversión para la salud pública con hardware médico de código abierto. Gaceta Sanitaria. 2015; 29(4), 319.

6. Kim AD, Ebramzadeh E, Chen JB, Bengs BC. Implant cost awareness of analogous intramedullary and plate devices among orthopaedic surgeons and residents in a public university hospital. Current Orthopaedic Practice. 2015;26(5):509-15.

7. Boldrin M, Levine DK. The economics of ideas and intellectual property. Proceedings of the National Academy of Sciences of the United States of America. 2005;102(4):1252-6.

8. Lemley MA. Property, intellectual property, and free riding. Tex L. Rev. 2004;83:1031.

9. Weber S. The Success of Open Source. Cambridge, MA: Harvard University Press; 2004.

10. Pearce JM. Building research equipment with free, open-source hardware. Science. 2012;337(6100):1303-4.

11. Hienerth C, von Hippel E, Jensen MB. User community vs. producer innovation development efficiency: A first empirical study. Research Policy. 2014;43(1):190-201.

12. Dunn AG, Day RO, Mandl KD, Coiera E. Learning from hackers: Open-source clinical trials. Science Translational Medicine. 2012;4(132):132cm5.

13. Estrin D, Sim I. Open mHealth architecture: An engine for health care innovation. Science 2010;330: 759-760.

14. Wood F, Guinter T. Evolution and implementation of the CDISC Study Data Tabulation Model (SDTM). Pharmaceutical Programming, 2008; 1:20-27.

15. Nosek BA, Alter G, Banks GC, Borsboom D, Bowman SD, Breckler SJ, Buck S, Chambers CD, Chin G, Christensen G, Contestabile M. Promoting an open research culture: Author guidelines for journals could help to promote transparency, openness, and reproducibility. Science. 2015;348(6242):1422.

16. Pearce JM. Open-Source Lab: How to Build Your Own Hardware and Reduce Research Costs, 2014, Elsevier:Amsterdam.

17. Baden T, Chagas AM, Gage G, Marzullo T, Prieto-Godino LL, Euler T. Open Labware: 3-D Printing Your Own Lab Equipment. PLoS Biol. 2015;13(3):e1002086.

18. Wijnen B, Anzalone GC, Pearce JM. Open-source mobile water quality testing platform. Journal of Water, Sanitation and Hygiene for Development. 2014;4(3):532-7.

19. Gualda E, Moreno N, Tomancak P, Martins GG. Going" open" with Mesoscopy: a new dimension on multi-view imaging. Protoplasma. 2014;251(2):363-72.

20. Pearce. Return on Investment for Open Source Hardware Development. Science and Public Policy. (in press) DOI :10.1093/scipol/scv034 